\title{
Seudotumor abdominal secundario a oblito quirúrgico
}

Abdominal pseudotumor secondary to surgical obliteration

Gabriela Espinosa ${ }^{1}$, Virginia Irigoyen ${ }^{2}$, Mauricio Pontillo ${ }^{3}$, Gustavo Rodríguez ${ }^{4}$

DOI $10.31837 /$ cir.urug/4.2.8

Recibido: 20 de mayo de 2020

Aceptado: 04 de julio de 2020

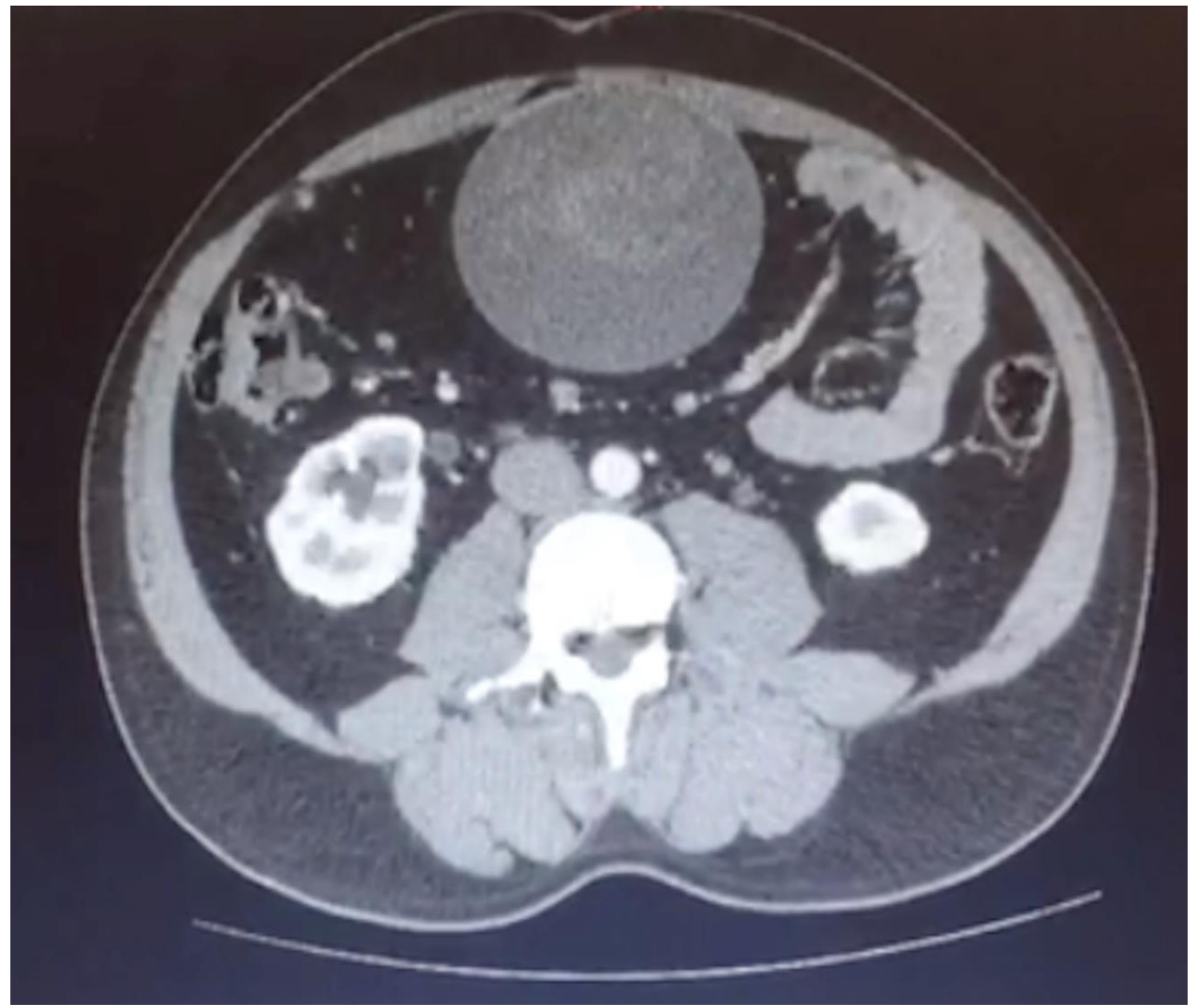

${ }^{1-4}$ Clínica Quirúrgica 2, Hospital Maciel, Facultad de Medicina, Universidad de la República, Montevideo, Uruguay gabrielaespinosa@msn.com 
El oblito o retención de cuerpo extraño después de un procedimiento quirúrgico es un problema real, vigente y prevenible que afecta la seguridad del paciente quirúrgico.

Se presenta el caso de un paciente de 42 años, colecistectomizado por vía laparotómica de urgencia hace 3 años que consulta por una tumoración centro-abdominal de un año de evolución indolora, de crecimiento progresivo, sin alteración de los tránsitos. La misma es intraabdominal, redondeada de $10 \mathrm{~cm}$ de diámetro. Se solicitó estudio tomográfico que confirma el hallazgo y se decide la exploración mediante laparotomía que confirma la presencia de una compresa quirúrgica.

El paciente evoluciona favorablemente.

Es importante adoptar una cultura de prevención, mediante la vigilancia perioperatoria de los materiales e instrumentos utilizados durante el acto quirúrgico.

El oblito puede ocurrir en cualquier procedimiento y provocar acciones médico-legales contra el equipo tratante.

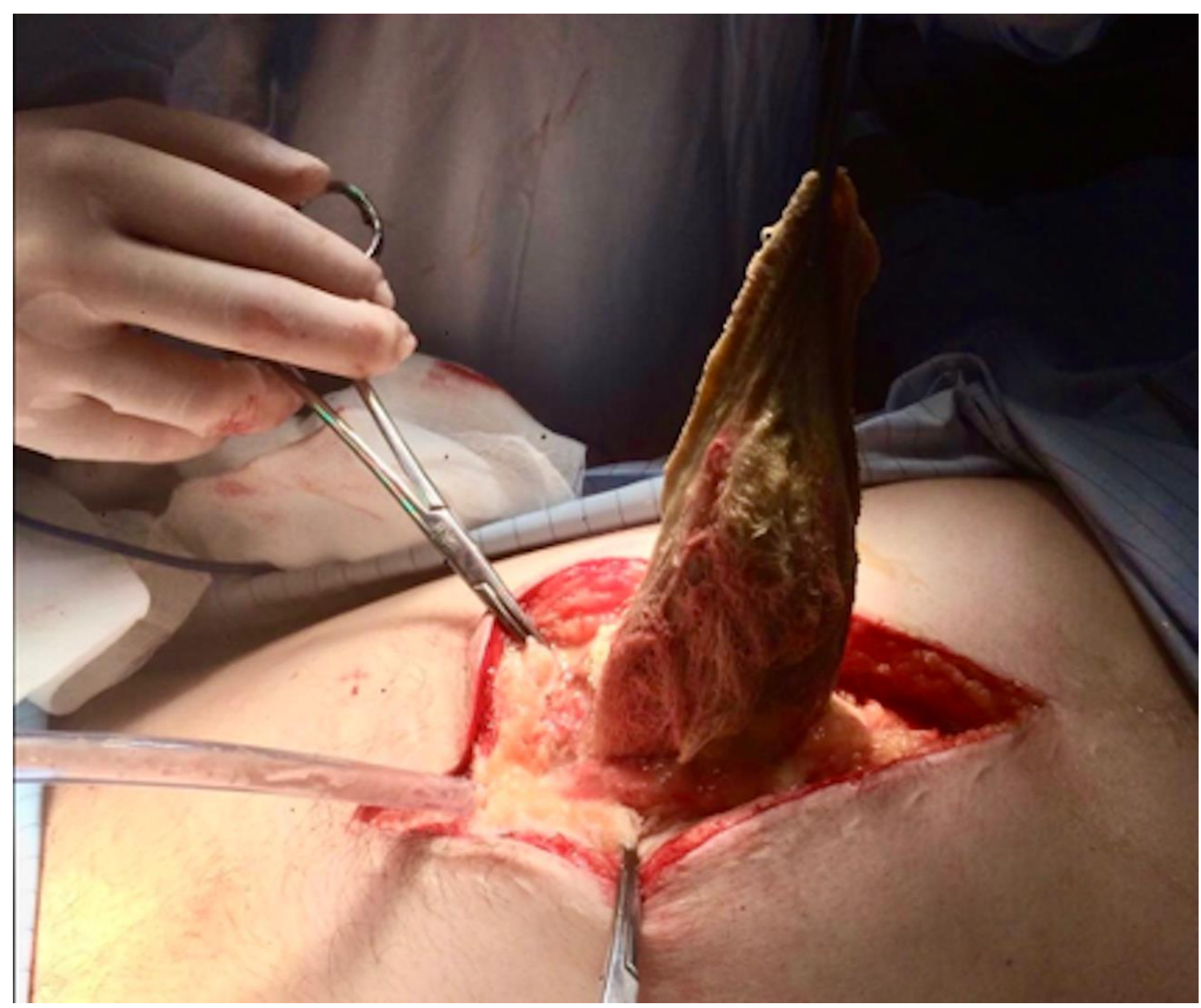

